\title{
Are Modal Conditions Necessary for Knowledge?
}

Mark Anthony L. Dacela

\begin{abstract}
Modal epistemic conditions have played an important role in post-Gettier theories of knowledge. These conditions purportedly eliminate the pernicious kind of luck present in all Gettier-type cases and offer a rather convincing way of refuting skepticism. This motivates the view that conditions of this sort are necessary for knowledge. I argue against this. I claim that modal conditions, particularly sensitivity and safety, are not necessary for knowledge. I do this by noting that the problem cases for both conditions point to a problem that cannot be fixed even by a revised similarity ranking or ordering of worlds. I offer as groundwork a set theoretical analysis of the profiles of the problem cases for safety and sensitivity. I then demonstrate that these conditions fail whenever necessary links constitutive of the epistemic situation actually obtain but are not modally preserved.
\end{abstract}

Keywords: Gettier problem, sensitivity, safety, modal epistemic conditions

\section{Introduction}

The Gettier problem ${ }^{1}$ is exemplified in cases where (1) the subject could have easily believed otherwise and in instances where (2) the proposition that the subject believes could have easily been false. These features motivate the intuition that in these cases some sort of $l u c k$ is involved: Given (1), the subject, it seems, only accidentally believes a true proposition; and given (2), the proposition that the subject believes seems only coincidentally true. In both instances we have a justified but luckily true belief.

Some epistemologists believe that this intuition is modal in nature: that ' $\mathrm{S}$ accidentally believes $p$ ' is explained by the intuition that there is a

${ }^{1}$ Gettier famously challenged the tripartite definition of knowledge, which requires the justified true belief (JTB) conditions, by citing two cases that, he claims, are not instances of knowledge, but in which all three conditions are satisfied. See Edmund Gettier, "Is Justified True Belief Knowledge?" Analysis, 23 (1963), 121-123.

(c) 2019 Mark Anthony L. Dacela

https://www.kritike.org/journal/issue 24/dacela june2019.pdf

ISSN 1908-7330 
possible world where $\mathrm{S}$ believes otherwise, while 'that $p$ is accidentally true' is explained by the intuition that there is a possible world where $p$ is false. Epistemologists who endorse this view usually drop the justification requirement of knowledge and replace it with a condition that is supposed to guarantee the connection between a person's justification for believing a proposition and the truth of the proposition he or she believes. It is assumed that such condition guarantees a stronger connection between $S$ 's justification for believing $p$ and the truth of $p$. If correct, this would mean that in any instance of knowledge, $S$ would not have easily believed otherwise, and that $p$ would not have easily been false. Or, in modal terms, that in nearby possible worlds, $S$ would still believe that $p$ and $p$ would still be true. What these epistemologists propose is a counterfactual or modal analysis of knowledge that requires counterfactual or modal conditions.

I argue here that modal conditions, particularly sensitivity and safety, are not necessary for knowledge. I do this by examining the profiles of problem cases for sensitivity and safety, noting that these cases actually point to a more serious problem than that of having a vague world-similarity criterion. I ground my argument on an analysis that treats the epistemic situation as a set which members are necessarily linked. I claim that these conditions fail whenever these necessary links that are constitutive of epistemic situations actually obtain but are not modally preserved.

\section{Modal Epistemic Conditions} knowing:

Robert Nozick $^{2}$ offers the following as necessary conditions for

C1: If $p$ weren't true, $\mathrm{S}$ wouldn't believe that $p$. (Variation condition)

C2: $\quad$ If $p$ were true, $\mathrm{S}$ would believe it. (Adherence condition)

$\mathrm{C} 1$ and $\mathrm{C} 2$ require sensitivity to the truth-value of the proposition. These conditions ask us to consider the status of the belief in situations that would obtain if the proposition is false, and if it remains true. Nozick requires that the belief be made sensitive to the truth-value of the proposition, such that if the proposition were false, the subject would not have believed it, and if the proposition remained true in a slightly different situation, the subject would have believed it still.

\footnotetext{
${ }^{2}$ Robert Nozick, Philosophical Explanations (Cambridge, MA: Harvard University Press, 1981).

(c) 2019 Mark Anthony L. Dacela

https://www.kritike.org/journal/issue 24/dacela june2019.pdf

ISSN 1908-7330
}

(c) $)$ BY-NC-ND 
Sosa, ${ }^{3}$ on the other hand, offers the following conditions as an alternative to Nozick's sensitivity condition: ${ }^{4}$

C3: $\quad$ S would believe that $p$ only if it were so that $p$.

Or alternatively,

C4: $\quad$ S would not believe that $p$ without it being the case that $p$.

C3 requires us to check close possible worlds where the subject believes the proposition and see if in those worlds the proposition that the subject believes is true. Or close possible worlds where the subject does not believe the proposition and see if in those worlds the proposition is false (C4).

\section{Profiles of Sensitivity and Safety Counterexamples}

I categorize problem cases for sensitivity and safety into three types:

(1) A-TYPE: 5 S has strong justification for believing $p$ and $p$ is true.

A-type cases involve a subject who has a strong justification for believing a true proposition, which makes his or her belief strongly justified. Justification is strong if the subject's evidence is almost conclusive. I place under this category the problem cases offered by Vogel and later Sosa, Gellman, and Briggs and Nolan. ${ }^{6}$ In A-type cases, the subject's belief is internally justified, insofar as the subject has access to the evidence that supports his or her belief. And as far as there are no (actual) defeaters in the description of the case, Atype beliefs are actually undefeated. Thus, in the actual world, the belief is both

${ }^{3}$ Ernest Sosa, "How to Defeat Opposition to Moore," Philosophical Perspectives, 13 (1999), 141-153.

${ }^{4}$ The safety condition is strikingly similar to Nozick's conditions. However, they are not logically equivalent since contraposition is invalid for counterfactuals.

${ }^{5}$ For a more extensive discussion of these cases see Mark Anthony Dacela, "Where Sensitivity Don't Work," Suri, 6:2 (2017), 110-123.

${ }^{6}$ For instance, see counterexamples which may be dubbed as the following: (1) "Garbage Chute" in Jonathan Vogel, "Tracking, Closure, and Inductive knowledge," in The Possibility of Knowledge: Nozick and his Critics, ed. by Luper-Foy Steven (Lanham, MD: Rowman \& Littlefield, 1987) and Ernest Sosa, "How to Defeat Opposition to Moore," Philosophical Perspectives, 13 (1999), 141-153; (2) "Mars" see Jerome Gellman, "A New Gettier Type of Refutation of Nozick's Analysis of Knowledge," Principia, 8:1 (2004), 279-283, and (3) "Mad," (4) "Bad," and (5) "Dangerous" in Rachael Briggs and Daniel Nolan, "Mad, bad and dangerous to know," Analysis, 72:2 (2012), 314-316.

(c) 2019 Mark Anthony L. Dacela https://www.kritike.org/journal/issue 24/dacela june2019.pdf ISSN 1908-7330 
internally justified and undefeated, such that no contrary evidence is given or accessible to the subject. Proponents of these counterexamples count as close worlds those in which the subject holds the same evidence, so the actual belief-characteristics are extended to these worlds. Worlds in which the subject does not believe the proposition are excluded from the set of relevant worlds, while worlds in which the proposition is true and the subject believes it are counted as close. A-type beliefs then turn out to be insensitive, but safe.

(2) B-TYPE: $\mathbf{S}$ forms belief $p$ via method $m, m$ is conditionally reliable ( $m$ is unreliable in a possible circumstance $r$ that almost obtained) and $p$ is true.

B-type cases involve a subject who forms his or her belief using a conditionally reliable method. A method is conditionally reliable if in case there is a possible circumstance where it fails to be reliable. I place under this category problem cases offered by Baumann, Neta and Rohrbaugh, Cosmeña, and Freitag. ${ }^{7}$ In these cases, the subject is unaware of the method's conditional reliability. Btype beliefs are internally justified but are factually defeated. Factual defeaters are true propositions that are unknown to the subject at the time he or she forms his or her belief. The presence of factual defeaters generates two analyses for B-type beliefs: (1) they are either taken as internally justified but almost defeated or (2) internally justified and undefeated. It all depends on how serious one takes the threat of factual defeat. Proponents of these counterexamples count worlds in which the subject holds the same evidence so the belief-characteristics extend to close possible worlds. However, if (1), then the set of close worlds include those in which S's belief is defeated. If (2), then the set excludes them. If (1), B-type beliefs are insensitive and unsafe; if (2), they are insensitive but safe.

(3) C-TYPE: S forms his or her belief $p$ via method $m$ with unstable reliability (at any time $t$ method $m$ is unreliable), and $p$ is true.

C-type cases involve a subject who forms his or her belief using a method that has unstable reliability. A method's reliability is unstable if at any time it can be unreliable. I place under this category the problem case offered by

7 See counterexamples that may be called the following (1) "Mask" in Peter Baumann, "Is Knowledge Safe?" American Philosophical Quarterly, 45:1 (2008), 19-30; (2) "Water" and (3) "Flashes" in Ram Neta and Guy Rohrbaugh, "Luminosity and the Safety of Knowledge," Pacific Philosophical Quarterly, 85 (2004), 396-406; (4) "Halloween" in Juan Comesaña, "Unsafe knowledge," Synthese, 146 (2005), 395-404; (5) "3/6 Clock" in Wolfgang Freitag, "Safety, Sensitivity and 'Distant' Epistemic Luck," Theoria, 80:1 (2014), 44-61.

(C) 2019 Mark Anthony L. Dacela

https://www.kritike.org/journal/issue 24/dacela june2019.pdf

ISSN 1908-7330

(c) ) BY-NC-ND 
Bogardus. ${ }^{8}$ In these cases, the subject is internally justified but factually defeated: he or she is not aware that reliability of his or her belief-forming method is unstable. C-type beliefs are internally justified but factually defeated. Proponents of these counterexamples count as close worlds those worlds in which the subject holds the same evidence, so the beliefcharacteristics are extended to these worlds. Relevant worlds include worlds in which the subject holds a justified and true belief but is factually defeated, and worlds in which he or she holds a justified false belief. Worlds in which the subject does not believe the proposition are not considered relevant. Ctype beliefs are insensitive and unsafe.

\section{Epistemic Situation and its Constitutive Links: Preliminary Analysis}

\section{Close Epistemic Worlds and the Ceteris Paribus Set}

One of the problems for sensitivity and safety is the seeming lack of a clear, nonarbitrary similarity criterion or closeness ranking that determines which worlds are similar or close. Counterexamples to safety and sensitivity capitalize on this deficiency and demonstrate very clearly how it questions the warrantedness of these views. The problem in brief is that if the criterion is too strict, say, we consider close worlds only those that are exactly similar to the actual world, then they become trivial conditions. Given such a criterion, the actual world would be the only world included in the set of close worlds. If the criterion is not strict but too narrow, say, we consider close worlds only those in which certain epistemic details similarly obtain while other nonepistemic details vary, then some relevant worlds will not be included in the set of close worlds; also, this set will be limited to worlds that only differ in terms of some epistemically irrelevant facts. If the criterion is too broad, then it fails to properly discriminate between worlds. It seems then that whichever criterion we take these conditions to have, there would be problem cases.

To appreciate the problem, let's make a distinction between close epistemic worlds and close worlds in general. ${ }^{9}$ Initially, we can take the former as a subset of the latter: a close epistemic world is a close world, but not all close worlds are close epistemic worlds. What are close worlds? These are worlds

\footnotetext{
8 Bogardus, for instance, offered his "Atomic Clock" counterexample. See Tomas Bogardus, “Knowledge Under Threat," Philosophy and Phenomenological Research, 88:2 (2014): 289313.

${ }^{9}$ For a more thorough discussion of the modal semantics at work in both sensitivity and safety, see Robert Stalnaker, "A Theory of Conditionals," in Studies in Logical Theory, ed. by Nicholas Rescher (Oxford: Blackwell, 1968), 98-112 and David Lewis, Counterfactuals (Oxford: Blackwell Publishers, 1973).
}

(c) 2019 Mark Anthony L. Dacela https://www.kritike.org/journal/issue 24/dacela june2019.pdf ISSN 1908-7330 
similar to the actual world. All other things being equal, a world where I am typing on my computer is close to the actual world where I am doing the exact same thing. However, there are many possible worlds in which I am typing on my computer:

Worlds in which I am drinking coffee while typing on my computer.

Worlds in which I am drinking soda while typing on my computer.

Which one is closer? To further limit the members of the set of close possible worlds, we need to identify more details, or facts that actually obtain. Suppose that in the actual world, I am drinking coffee while typing on my computer. If this is the case, then (1) is closer than (2). That is, all the other details being equal, worlds in which I am drinking coffee are closer to the actual world than those in which I am drinking soda. Hence, to determine which worlds are close, you need to identify what facts actually obtain. To limit the ceteris paribus set, or the set of details you take as equal across worlds, you have to qualify your description of the world in a way that identifies more details. If your description of the actual world is too general, then more worlds will be included in the set of close worlds. If you further qualify your description, then the members will be fewer. After enumerating the details that describe the actual world, it is important to identify which details you will include in the ceteris paribus set. You have to consider what things should be equal across worlds. If we exclude in the ceteris paribus set "drinking coffee," then both (1) and (2) are close worlds. But if we include this detail in the ceteris paribus set, then the set only includes (1). This briefly demonstrates how a similarity criterion can be seen as either arbitrary or trivial.

However, sensitivity and safety theories ask us to track not just any close worlds but close epistemic worlds, or those worlds in which the actual epistemic situation similarly obtains. Identifying these worlds requires that we describe the actual epistemic situation: the actual set of epistemically relevant details. However, the criterion problem also manifests here, for we still need to determine which of these epistemically similar worlds are close.

\section{Constitutive Epistemic Links}

I find it helpful in this analysis to think of a given epistemic situation as a set of epistemically relevant details. Take these details as the usual things epistemologists identify when they describe epistemic cases: the subject who believes the proposition, his or her belief, the evidence that led him or her to form his or her belief, his or her belief-forming method, the fact (or facts) that 
make the proposition true (or false), and the proposition the subject accepts (some cases also include defeaters). I am not claiming that this list is complete, but a typical description of an epistemic case identifies some or all of these details. These details are linked together and constitute an epistemic situation.

'Evidence' (e) refers to the things that led to the formation of the belief. Such that, given e, the subject forms belief $p$ :

$$
\mathrm{e} \rightarrow \mathrm{Bsp}
$$

While 'fact' (f) refers to a particular state of affairs that makes the proposition either true or false:

$$
\mathrm{f} \rightarrow p
$$

But e can also be though of as a set of particular evidences. Given set $\{\mathrm{e}\}$, the subject forms belief $p$ :

$$
\text { (a) }\{\mathrm{e}\} \rightarrow \text { Bsp }
$$

Given (a), members of set $\{e\}$ are necessary and sufficient conditions for the subject to form the belief (let ' $\rightarrow$ ' stand for implication and \{\} to the given set):

$$
[\{\mathrm{e}\} \rightarrow \mathrm{Bsp}] \rightarrow[\sim\{\mathrm{e}\} \rightarrow \sim \mathrm{Bsp}] .[\{\mathrm{e}\} \rightarrow \mathrm{Bsp}]
$$

Similarly, (f) can be thought of as a set of particular facts. Given set $\{f\}, p$ is true:

$$
\text { (b) }\{\mathrm{f}\} \rightarrow p
$$

Given (b), members of set $\{f\}$ are necessary and sufficient to make the proposition true:

$$
[\{\mathbf{f}\} \rightarrow p] \rightarrow[\sim\{\mathrm{f}\} \rightarrow \sim p] .[\{f\} \rightarrow p]
$$

This brief analysis makes explicit two very important features of an epistemic situation: (1) the subject's evidence for believing something is necessarily linked to the formation of his or her belief, and (2) facts that actually obtain are necessarily linked to the truth value of a proposition. Treating evidence and facts as sets will help demonstrate what these features imply about epistemic situations and the way we think about close epistemic worlds.

(c) 2019 Mark Anthony L. Dacela https://www.kritike.org/journal/issue 24/dacela june2019.pdf ISSN 1908-7330 


\section{Set Relations of Evidence and Facts}

It seems to me that the set of evidence and the set of facts have three possible relations. First, it is possible that all members of the given set of evidence are members of the given set of relevant facts (the term 'relevant' indicates that only facts that make the proposition true are included in this set) and vice versa. In this case, set $\mathrm{E}$ and set $\mathrm{F}$ are equivalent sets (let " $=$ " represent this set relationship, and let the letters inside \{\} stand for the members of the set and the letters outside \{\} for the name of the set):

$$
R_{1}: E\{a, b, c\}=F\{a, b, c\}
$$

If $R_{1}$ is the case, then to include in the ceteris paribus set (let * stand for this set) the set of evidence is to include the set of facts. In other words, given $R_{1}$, if all the members of set $\mathrm{E}$ are members of set ${ }^{*}$, then all members of set $\mathrm{F}$ are also members of set *

$$
\left[\left\{(\mathrm{E}=\mathrm{F}) .{ }^{*}\{\mathrm{E}\}\right] \rightarrow{ }^{*}\{\mathrm{~F}\}\right.
$$

Conversely, if all members of set $\mathrm{F}$ are members of set *, then, given $\mathrm{R}_{1}$, all members of set $\mathrm{E}$ are members of set ${ }^{*}$ :

$$
\left[(\mathrm{E}=\mathrm{F}) .{ }^{*}\{\mathrm{E}\}\right] \rightarrow{ }^{*}\{\mathrm{~F}\}
$$

So, if the given set of evidences imply that the subject believes the proposition and the given set of facts implies that the proposition is true (in other words, if the members of each set are necessary and sufficient conditions for either Bsp or $p$ to obtain), then, given $\mathrm{R}_{1}$, in a possible world in which all the evidences included in set $\mathrm{E}$ obtain, and those worlds in which all the facts included in set F obtain, the subject believes the proposition and the proposition is true (Let ' \#' indicate that the given equation obtains in a possible world where either E or F obtains):

$$
[(\mathrm{E}=\mathrm{F}) .(\mathrm{E} \rightarrow \mathrm{Bsp}) .(\mathrm{F} \rightarrow p)] \rightarrow[\#(\mathrm{E} \cdot \mathrm{Bsp} \cdot p) . \#(\text { F.Bsp.p })]
$$

Second, there may also be instances where no member of the given set of evidence is a member of the given set of relevant facts. In this case set $\mathrm{E}$ and set $\mathrm{F}$ are complement sets (let ' - ' indicate that these sets are exclusive:

$$
R_{2} E\{a, b, c\}-F\{d, e, f\}
$$


If $\mathrm{R}_{2}$ is the case, then if only members of $\mathrm{E}$ are included in the ceteris paribus set, then members of $\mathrm{F}$ are excluded from this set (recall: ${ }^{* \prime \prime}$ refers to the ceteris paribus set):

$$
\left[(\mathrm{E}-\mathrm{F}) .{ }^{*}\{\mathrm{E}\}\right] \rightarrow \sim\left[{ }^{*}\{\mathrm{~F}\}\right]
$$

Conversely, given $\mathrm{R}_{2}$, if only members of $\mathrm{F}$ are included in set *, then members of $\mathrm{E}$ are excluded:

$$
\left[(\mathrm{E}-\mathrm{F}) .{ }^{*}\{\mathrm{~F}\}\right] \rightarrow \sim\left[{ }^{*}\{\mathrm{E}\}\right]
$$

So, if the given set of evidence implies that the subject believes the proposition and the given set of relevant facts implies that the proposition is true, then, given $R_{2}$, in a possible world in which only set $E$ obtains, the subject believes the proposition and the proposition is false; and in a possible world in which only set $\mathrm{F}$ obtains, the proposition is true but the subject does not believe it:

$$
[(\mathrm{E}-\mathrm{F}) .(\mathrm{E} \rightarrow \mathrm{Bsp}) .(\mathrm{F} \rightarrow p)] \rightarrow[\#(\mathrm{E} \cdot \mathrm{Bsp} . \sim p) . \#(\mathrm{~F} . \sim \mathrm{Bsp} . p)]
$$

Lastly, it can also be the case that some members of either set are members of the other set. It may be the case that some members of the set of evidence are members of the set of facts and vice versa. In these cases, these sets are subsets of the other set (let ' $\subset$ ' represent this relation):

$$
\mathrm{R}_{3}: \mathrm{E}\{\mathrm{a}, \mathrm{b},\} \subset \mathrm{F}\{\mathrm{a}, \mathrm{b}, \mathrm{c}\} \vee \mathrm{F}\{\mathrm{a}, \mathrm{b},\} \subset \mathrm{E}\{\mathrm{a}, \mathrm{b}, \mathrm{c}\}
$$

If set $\mathrm{E}$ is a subset of set $\mathrm{F}$, then only members of set $\mathrm{E}$ are included in the ceteris paribus set, some but not all members of set $\mathrm{F}$ will also be included, so set $\mathrm{F}$ is excluded:

$$
\left[(\mathrm{E} \subset \mathrm{F}) .{ }^{*}\{\mathrm{E}\}\right] \rightarrow \sim\left[{ }^{*}\{\mathrm{~F}\}\right]
$$

If set $\mathrm{F}$ is a subset of $\mathrm{E}$, include set $\mathrm{F}$ in the ceteris paribus set, and some but not all members of set $\mathrm{E}$ are included, so set $\mathrm{E}$ is excluded:

$$
\left[(\mathrm{F} \subset \mathrm{E}) .{ }^{*}\{\mathrm{~F}\}\right] \rightarrow \sim\left[{ }^{*}\{\mathrm{E}\}\right]
$$

Thus, if the given set of evidence implies that the subject believes the proposition, and the given set of relevant facts implies that the proposition is true, then, if set $\mathrm{E}$ is a subset of $\mathrm{F}$ (all members of $\mathrm{E}$ are members of $\mathrm{F}$ but $\mathrm{E}$ and $\mathrm{F}$ are not equivalent sets), in a possible world in which only set $\mathrm{E}$ obtains, the subject believes the proposition and the proposition is false, and in a

(c) 2019 Mark Anthony L. Dacela https://www.kritike.org/journal/issue 24/dacela june2019.pdf ISSN 1908-7330 
possible world in which only set F obtains, the proposition is true and the subject believes it:

$$
[(\mathrm{E} \subset \mathrm{F}) .(\mathrm{E} \rightarrow \mathrm{Bsp}) .(\mathrm{F} \rightarrow p)] \rightarrow[\#(\mathrm{E} . \text { Bsp. } \sim p) . \#(\text { F.Bsp.p })]
$$

And if set $F$ is a subset of $E$, (all members of $F$ are members of $E$ but $E$ and $F$ are not equivalent sets), in a possible world in which only members of set $\mathrm{F}$ obtains, the proposition is true but the subject does not believe it, and in a possible world in which only set $\mathrm{E}$ obtains, the proposition is true and the subject believes it:

$$
[(\mathrm{F} \subset \mathrm{E}) .(\mathrm{E} \rightarrow \mathrm{Bsp}) .(\mathrm{F} \rightarrow p)] \rightarrow[\#(\mathrm{~F} . \sim \mathrm{Bsp} . p) . \#(\text { E.Bsp.p })]
$$

\section{Why Modal Conditions Fail?}

Identifying the necessary links and their implications in the way we think about epistemic situations and close epistemic worlds will help us explain why sensitivity and safety fail in the case profiles we identified earlier.

\section{A-Type Cases}

Recall that in A-type cases, the subject is strongly justified in believing a true proposition. A-type beliefs are insensitive but safe. A-type beliefs are internally justified. There is nothing in the subject's set of evidence (set E) that makes the proposition that he or she accepts false: there's nothing in $E$ that is contrary to $\mathrm{p}$. Also in the actual world, the belief is undefeated, since the set of given facts (set F) makes the proposition true.

Proponents of these counterexamples claim that A-type beliefs are insensitive since in close worlds in which $p$ is false, the subject still believes it. Recall that the variation condition of sensitivity requires us to check close not$p$ worlds and see if in those worlds the subject does not believe the same proposition. What worlds are these? This should at least include worlds in which a similar epistemic situation obtains. The latter pertains to the set that includes the same subject, belief, method, evidence, facts, and proposition. The ceteris paribus set is then limited to worlds in which the subject is in a similar epistemic situation. We cannot include in this set the relevant facts that actually obtain, since we are checking for close worlds in which the proposition is false. If we include the set of relevant facts (set $\mathrm{F}$ ) in the ceteris paribus set, then the worlds we will identify are worlds in which the proposition is true. 
If the set of relevant facts make the proposition true:

$$
\mathrm{F} \rightarrow p
$$

Then in worlds in which set F obtains, $p$ is true. So we are looking for worlds in which the subject's epistemic situation is similar to his or her actual epistemic situation, except, in this possible situation, set F does not obtain. It seems then that sensitivity requires us to look for worlds in which, except for set $\mathrm{F}$, everything else that actually obtains, obtains. If set $\mathrm{E}$ is taken to include everything that led to the formation of the belief, the ceteris paribus set only includes set E. But if the subject's set of evidence implies that the subject accepts the proposition ( $\mathrm{E} \rightarrow \mathrm{Bsp}$ ), then if only members of set $\mathrm{E}$ are included in the ceteris paribus set, excluding all members of set F, in all these 'close' worlds, the subject falsely believes the proposition (Bsp. $\sim p$ ):

$$
\left[(\mathrm{E}-\mathrm{F}) .(\mathrm{E} \rightarrow \mathrm{Bsp}) .(\mathrm{F} \rightarrow p) .{ }^{*}\{\mathrm{E}\}\right] \rightarrow \#(\mathrm{E} \cdot \mathrm{Bsp} . \sim p)
$$

As a result, A-type beliefs are insensitive. Note that set $\mathrm{E}$ and $\mathrm{F}$ are taken here as complement sets.

Sensitivity theorists have two possible moves here: either they claim that A-type beliefs do not qualify as knowledge because they are insensitive, thus accepting the result, or they can show that A-type beliefs are sensitive. Either way, sensitivity will have serious problems. Let's examine these moves.

First, note that A-type beliefs are fallible beliefs. Call a belief "fallible" if and only if the subject's evidence for accepting or believing a proposition is compatible with the proposition being false. The evidence does not guarantee the truth of the proposition. In cases of this sort, the set of evidence is not equivalent to the set of relevant facts. If these two are equivalent sets, then it is impossible for the proposition to be false, given the same set of evidence. Thus, sensitivity theorists can take A-type beliefs as having either complementary $\mathrm{E}$ and F sets, or E and F subsets. They can either think of them as beliefs that are formed within an epistemic circumstance in which the subject's evidence is completely different from the relevant facts that make the proposition true, or formed within an epistemic circumstance in which some of the subject's evidence are included in the set of particular facts that makes the proposition true. So if in the actual world the subject has a fallible belief, then the set relations of E and F are either (recall '@' indicates that the sets obtain in the actual world):

$$
\begin{aligned}
& \text { Complement Sets }\left(R_{2}\right): @ E\{a, b, c\}-F\{x, y, z\} ; \text { or } \\
& \text { Subsets }\left(R_{3}\right): @ E\{a, b\} \subset F\{a, b, c\} \vee F\{a, b, c\} \subset E\{a, b,\}
\end{aligned}
$$

(c) 2019 Mark Anthony L. Dacela https://www.kritike.org/journal/issue 24/dacela june2019.pdf ISSN 1908-7330 
If they are complement sets, then if set $\mathrm{E}$ but not set $\mathrm{F}$ is included in the ceteris paribus set, so that in "close worlds" the subject falsely believes the proposition:

$$
\left[(\mathrm{E}-\mathrm{F}) \cdot\left((\mathrm{E} \rightarrow \mathrm{Bsp}) \cdot(\mathrm{F} \rightarrow p) .{ }^{*}\{\mathrm{E}\}\right] \rightarrow \#(\mathrm{E} \cdot \mathrm{Bsp} . \sim p)\right.
$$

So A-type beliefs and all fallible beliefs will always be insensitive.

If they are subsets, you still have to exclude all the members of set $\mathrm{F}$ in the ceteris paribus set, otherwise $p$ will obtain instead of not $\sim p$ (remember that sensitivity requires us to check worlds in which not $\sim p$ obtains). But you can include members of $\mathrm{F}$ that are members of $\mathrm{E}$ (given that all the members of $\mathrm{F}$ are necessary and sufficient conditions for $p$ ). In which case, the ceteris paribus set is the intersection of set $\mathrm{E}$ and $\mathrm{F}$ (recall: $\cap{ }^{\prime}$ represent this relation):

$*\{\mathrm{E} \cap \mathrm{F}\}$

If this is taken as the ceteris paribus set, then in 'close possible worlds', the subject does not believe the proposition, and the proposition is false. In those worlds, not all members of set $\mathrm{E}$ and $\mathrm{F}$ obtain, and given that $\mathrm{E}$ is a necessary condition for the subject's believing the proposition, and F is a necessary condition for the proposition being true:

$$
\left[(\mathrm{E} \supset \mathrm{F})(\mathrm{E} \rightarrow \mathrm{Bsp}) .(\mathrm{F} \rightarrow \mathrm{p}) .{ }^{*}\{\mathrm{E} \cap \mathrm{F}\}\right] \rightarrow \#[\{\mathrm{E} \cap \mathrm{F}\} . \sim \mathrm{Bsp} . \sim \mathrm{p}]
$$

So A-type beliefs and all fallible beliefs will always be sensitive.

Thus, if sensitivity theorists want to claim that A-type beliefs are insensitive, then they would have to think of sets $\mathrm{E}$ and $\mathrm{F}$ as complement sets $\left(\mathrm{R}_{2}\right)$ in A-type cases. If they claim that A-type beliefs are sensitive, then they would have to think of these sets as subsets $\left(R_{3}\right)$ in A-type cases. If in A-type cases $\mathrm{E}$ and $\mathrm{F}$ are complement sets, then fallible beliefs are always sensitive. If in A-type cases $\mathrm{E}$ and $\mathrm{F}$ are subsets, then fallible beliefs are always insensitive.

If fallible beliefs are always insensitive, and only sensitive beliefs qualify as knowledge, then all justified fallible beliefs, i.e., beliefs with evidential support but possibly false, do not qualify as knowledge. These include those that are strongly justified, or beliefs with strong evidential support. But if these beliefs do not qualify as knowledge, then beliefs in ordinary propositions like "I have hands" also do not qualify as knowledge; these beliefs are fallible. This contradicts claim that these propositions are sensitive. ${ }^{10}$

\footnotetext{
${ }^{10}$ See Nozick, Philosophical Explanations, 181.

(C) 2019 Mark Anthony L. Dacela

https://www.kritike.org/journal/issue 24/dacela june2019.pdf

ISSN 1908-7330
}

(c) BY-NC-ND 
If fallible beliefs are always sensitive, then Gettiered beliefs, which are justified fallible beliefs, are sensitive beliefs. Sensitivity theorists will then be forced to accept as knowledge the very beliefs they had intended to disqualify as knowledge.

Proponents of safety claim that A-type beliefs are safe since in close worlds in which $p$ is true, the subject believes the proposition. What worlds are these? Note that, unlike in the case of sensitivity, we are checking worlds in which the subject believes that proposition. So we have to include set $\mathrm{E}$ in the ceteris paribus set. Given that E implies that the subject believes the proposition:

$$
(\mathrm{E} \rightarrow \mathrm{Bsp}) \rightarrow \#(\mathrm{E} \rightarrow \mathrm{Bsp})]
$$

But what about the set of relevant facts, i.e., set F? Should F be included in the ceteris paribus set? It seems that it should be included. If not, then in all 'close worlds' the subject falsely believes the proposition. All A-type beliefs are unsafe:

$$
\left[(\mathrm{E}-\mathrm{F}) .(\mathrm{E} \rightarrow \mathrm{Bsp}) .(\mathrm{F} \rightarrow p) .{ }^{*}\{\mathrm{~F}\}\right] \rightarrow[\#(\mathrm{~F} \cdot \mathrm{Bsp} . \sim p)]
$$

And this is not the result safety theorists have in mind. But even if we suppose that they do accept this result. If all A-type beliefs are unsafe, and safety is a necessary requirement for knowledge, then all justified fallible beliefs do not qualify as knowledge, same problems with sensitivity.

However, you cannot also include both $\mathrm{E}$ and $\mathrm{F}$ in the ceteris paribus set. If you do, then all A-type beliefs will be safe (including Gettiered beliefs). Since in 'close worlds', worlds in which E and F obtain, the subject truly believes $p$ :

$$
\left[(\mathrm{E}-\mathrm{F}) .(\mathrm{E} \rightarrow \mathrm{Bsp}) .(\mathrm{F} \rightarrow p) .{ }^{*}\{\mathrm{~F} \cdot \mathrm{E}\}\right] \rightarrow \#(\mathrm{~F} . \mathrm{E} . \mathrm{Bsp} \cdot p)
$$

Moreover, if both $\mathrm{E}$ and $\mathrm{F}$ are included in the ceteris paribus set, then the actual world will be the only member of the set of close worlds, unless worlds that only vary in some epistemically irrelevant details are included in this set: worlds in which both $\mathrm{E}$ and $\mathrm{F}$ obtain and some nonepistemic circumstance vary. This move will make safety a trivial condition.

There's another way: include in the ceteris paribus set only members of set $\mathrm{E}$ that are also members of F. In other words, the intersection of set $\mathrm{E}$ and $F$ (recall: ' $\mathrm{'}$ ' represents this relation, and '*' indicates that the set obtains in the actual world):

$*\{\mathrm{E} \cap \mathrm{F}\}$

(c) 2019 Mark Anthony L. Dacela https://www.kritike.org/journal/issue 24/dacela june2019.pdf ISSN 1908-7330 
Note that if this is done, then it is supposed that the epistemic situation in Atype cases is such that $\mathrm{E}$ and $\mathrm{F}$ are subsets, for if they are equivalent sets, then the ceteris paribus set will include all members of both sets, and if they are complement sets then ceteris paribus set will be an empty set. But, if the ceteris paribus set only includes the intersection of $\mathrm{E}$ and $\mathrm{F}$, then in 'close worlds' the subject does not believe false proposition $p$, given that set E implies the subject's belief and F implies that the proposition is true:

$$
\left.\left[(\mathrm{E}-\mathrm{F}) .(\mathrm{E} \rightarrow \mathrm{Bsp}) .(\mathrm{F} \rightarrow p) .{ }^{*}\{\mathrm{E} \cap \mathrm{F}\}\right] \rightarrow \#[\{\mathrm{E} \cap \mathrm{F}\} . \sim \mathrm{Bsp} . \sim p)\right]
$$

But safety requires us to track worlds in which the subject believes the proposition, and not worlds in which he or she did not. This move, again, trivializes safety.

\section{B-type and C-type Cases}

Recall that B-type beliefs are either internally justified but almost defeated or internally justified and undefeated, depending on how serious the threat of factual defeat is taken to be (recall: a belief is factually defeated if and only if unknown to the subject, there is a true proposition that defeats his or her belief). Meanwhile, in C-type cases the subject's belief-forming method has unstable reliability since at any time it can fail to produce a true belief. The factual defeater in B-type and C-type cases is the true proposition, "my method is conditionally reliable." The dilemma comes in two ways: (1) if the subject had known that his or her belief forming method is conditionally reliable then he or she would not have believed the proposition, and (2) if it had been the case that the given circumstance is such that it makes the subject's belief-forming method unreliable, he or she would have falsely believed the proposition. Note that in both cases, nothing actually defeats the subject's belief. That his or her method is conditionally reliable, does not take away the fact that it actually works, given the subject's actual circumstance. The conditional reliability of the subject's belief forming method does not necessarily make the proposition false. It also does not make the subject's belief any less justified, since it is unknown to him or her that the method is conditionally reliable.

So how do we determine the worlds close to the actual world in which these cases obtain? Proponents of this counterexample seem to suggest that given the conditional reliability of the subject's belief-forming method, the 'closest' worlds are those in which the method fails to produce a true belief. If this is the case, the belief is unsafe. On the other hand, safety theorists can argue that (if the move is to hold that these beliefs are safe) the "close worlds" 
are those in which the threat of epistemic defeat is also unrealized, given that that threat is unrealized in the actual world. So, the question really is whether or not the fact that there is an unrealized but potential threat of epistemic defeat in the actual world makes possible worlds in which that threat is realized relevantly close.

To answer this, let us ask first if this unrealized but potential threat is included in the set of the subject's evidence or the set of relevant facts that make the proposition true. Do we treat it as part of the evidence that led to the formation of the subject's belief or as a particular fact that makes the proposition false? Safety theorists can claim that such a threat cannot be considered as part of the subject's evidence for two reasons. First, the subject does not even know that threat exists. Second, the fact that the threat is unrealized does not have anything to do with the formation of the subject's belief-he would have formed the same belief even if it were realized. On the other hand, the proposition would have been false if the threat were realized. So, that in the given circumstance the threat is unrealized, is a relevant fact that makes the proposition true.

If safety theorists treat this unrealized threat as a member of the set of relevant facts, B-type beliefs will turn out safe, but not without trivializing safety. Note two things. First, like A-type beliefs, these beliefs are justified fallible beliefs. The subject's evidence is compatible with the proposition being false. Second, also like in A-type cases, sets E and F in B-type and C-type cases are not equivalent sets: case in point, the unrealized threat which is included in set $F$ is excluded in set $E$. So either they are complement sets or subsets:

$$
\begin{aligned}
& \text { Complement Sets }\left(R_{2}\right): @ E\{a, b, c\}-F\{x, y, z\} ; \text { or } \\
& \text { Subsets }\left(R_{3}\right): @ E\{a, b\} \subset F\{a, b, c\} v F\{a, b\} \subset E\{a, b, c\}
\end{aligned}
$$

If they are complement sets, then if set $\mathrm{E}$ but not set $\mathrm{F}$ is included in the ceteris paribus set, in 'close worlds' (recall that this is the set of the things we hold equal across worlds) the subject falsely believes the proposition (recall ' - ' indicates that the given sets are complement sets):

$$
\left[(\mathrm{E}-\mathrm{F}) .\left((\mathrm{E} \rightarrow \mathrm{Bsp}) .(\mathrm{F} \rightarrow p) .{ }^{*}\{\mathrm{E}\}\right] \rightarrow \#(\mathrm{E} \cdot \mathrm{Bsp} . \sim p)\right.
$$

Fallible beliefs will always be unsafe. If they are subsets, and the intersection of sets $\mathrm{E}$ and $\mathrm{F}$ is included, then in 'close worlds' the subject does not believe the proposition and the proposition is false, since not all members of both sets obtain in these worlds:

$$
\left[(\mathrm{E} \supset \mathrm{F})(\mathrm{E} \rightarrow \mathrm{Bsp}) .(\mathrm{F} \rightarrow p){ }^{*}\{\mathrm{E} \cap \mathrm{F}\}\right] \rightarrow \#[\{\mathrm{E} \cap \mathrm{F}\} . \sim \mathrm{Bsp} . \sim p]
$$




\section{Fallible Beliefs will Always be Unsafe}

Now notice that safety theorists have to include set $\mathrm{E}$ in the ceteris paribus set, since safety requires us to check for worlds in which the subject believes the proposition, and E implies that the subject believes the proposition:

$$
(\mathrm{E} \rightarrow \mathrm{Bsp}) \rightarrow \#(\mathrm{E} . \mathrm{Bsp})
$$

Set $\mathrm{F}$ also have to be included, otherwise, given that not-F implies that the proposition is false, in all 'close worlds' the subject falsely believes the proposition. So all B-type and C-type beliefs are unsafe:

$$
\left[(\mathrm{E}-\mathrm{F}) .(\mathrm{E} \rightarrow \mathrm{Bsp}) .(\mathrm{F} \rightarrow p) .{ }^{*}\{\mathrm{~F}\}\right] \rightarrow \#(\mathrm{E} \cdot \mathrm{Bsp} . \sim p)
$$

However, both $\mathrm{E}$ and $\mathrm{F}$ cannot be included in the ceteris paribus set; otherwise, all fallible beliefs will be safe (including Gettiered beliefs). Since in 'close worlds', worlds in which E and F obtain, the subject truly believe $p$ :

$$
\left[(\mathrm{E}-\mathrm{F}) .(\mathrm{E} \rightarrow \mathrm{Bsp}) .(\mathrm{F} \rightarrow p) .{ }^{*}\{\mathrm{~F} . \mathrm{E}\}\right] \rightarrow \#(\text { F.E. Bsp. } p)
$$

And again, if both $\mathrm{E}$ and $\mathrm{F}$ are included in the ceteris paribus set, then the actual world will be the only member of the set of close worlds, unless those worlds that only vary in some epistemically irrelevant details are included in this set (recall that these are worlds in which both $\mathrm{E}$ and $\mathrm{F}$ obtain and some nonepistemic circumstance vary).

Another move is to include in the ceteris paribus set the intersection of set $\mathrm{E}$ and $\mathrm{F}$ (recall: ' $\mathrm{n}$ ' represents this relation, and ' $\#$ ' indicates that the set obtains in the actual world):

$$
\#\{E \cap F\}
$$

But, if the ceteris paribus set only includes this, then in 'close worlds' the subject does not believe false proposition $p$. And, as I already explained in my analysis of A-type cases, this move trivializes safety:

$$
\left[(\mathrm{E}-\mathrm{F}) .(\mathrm{E} \rightarrow \mathrm{Bsp}) .(\mathrm{F} \rightarrow p) .{ }^{*}\{\mathrm{E} \cap \mathrm{F}\}\right] \rightarrow \#[\{\mathrm{E} \cap \mathrm{F}\} . \sim \mathrm{Bsp} . \sim p]
$$

Similar to my analysis of A-type beliefs, sensitivity theorists cannot claim that B-type and C-type beliefs are sensitive without either accepting that all fallible beliefs are sensitive or that all fallible beliefs are false. They cannot include both $\mathrm{E}$ and $\mathrm{F}$ in the ceteris paribus set, and they cannot limit this set to 
all members of set F. Both moves will trivialize sensitivity. If they include $\mathrm{E}$ only, in "close worlds," the subject falsely believes the proposition. So B-type and C-type beliefs and all fallible beliefs will always be insensitive, including our beliefs in ordinary propositions like 'I have hands'. If they limit the ceteris paribus set to the intersection of both sets, in 'close worlds' the subject does not believe the proposition, and the proposition is false. So B-type and C-type beliefs and all fallible beliefs are always sensitive, including Gettiered beliefs.

\section{Not Just a Criterion Problem}

The above analysis demonstrates why sensitivity and safety simply do not work in A-type, B-type, and C-type cases, but we can also extend the findings here to all fallible beliefs, or beliefs which evidential features are compatible with the falsity of its propositional object. Sensitivity and safety theorists cannot consistently claim that these beliefs do not qualify as knowledge, since they accept that at least some fallible beliefs do qualify as knowledge, such as our beliefs in ordinary propositions like "I have hands." But they cannot also consistently claim that they qualify as knowledge without trivializing the modal conditions they necessarily require for knowledge. While this problem implies the lack of a clear and adequate closeness criterion, it also points to a more serious problem, one that is not easily solved by a mere revision of the similarity criterion.

The fundamental problem I am referring to is that these modal conditions fail to recognize certain relational features that constitute epistemic situations. Namely, the constitutive significance of those details or set of evidence that led to the formation of the subject's belief and the state of affairs, or set of particular facts, that makes a given proposition true. These relational features are constitutive links that determine an epistemic situation.

Modal conditions require us to track possible worlds. To do this, we need to hold as equal across worlds certain details or features of an actual epistemic situation to check if certain links are modally preserved, in a way that seems to forget the constitutive significance of actually established links. And while the link between belief and fact is usually modally preserved, some actually established links are not, like the link between evidence and belief, the link between the set of relevant facts and the truth of a proposition, and the link between evidence and fact.

In a world in which the actual set of evidence is not given, the subject would not have formed the belief that he or she did form in the actual situation he or she is in, and in a world in which not all the relevant facts are given, the proposition would not have been true. However, as demonstrated in our analysis, that these links are not modally preserved does not necessarily mean that they do not exist in the actual situation, or in the

(c) 2019 Mark Anthony L. Dacela

https://www.kritike.org/journal/issue 24/dacela june2019.pdf

ISSN 1908-7330

(cc) BY-NC-ND 
epistemic circumstance that obtains in the actual world. Sensitivity and safety fail when actual links which are not modally preserved is sufficient for knowledge. And for this reason, these modal conditions are not necessary for knowledge.

\title{
Objections and Replies
}

Let us now consider some possible objections to my argument.

\section{Against Constitutive Links}

\author{
Objection 1: Epistemic links do not exist. \\ Objection 2: Epistemic links do not constitute \\ epistemic situations.
}

I reply that sensitivity and safety theorists need to assume that these links exist as constitutive elements of the epistemic situation or the modal conditions will not work. Sensitivity and safety theorists require necessarily that the link between belief and truth value of the proposition is modally preserved. But to check if this link is in fact modally preserved, they require us to check close possible worlds in which the proposition is false (sensitivity), or similar worlds in the subject believes the same proposition (safety). But one cannot consider a world "similar" without holding that while some details vary, some details are the same. Which "details" one holds the same and which ones vary will determine relevant epistemic features such as whether or not the subject believes the proposition, and whether or not the proposition is true. The details are linked to these features. If sensitivity and safety theorists do not accept this link, then identifying "close worlds" is going to be arbitrary. Recognizing this link is important in determining which details to hold the same across worlds, and which ones can vary. Sensitivity condition requires us to check if in 'close worlds' in which the proposition is false, the subject does not believe it. Which implies that one cannot hold the details that make the proposition true across worlds, one cannot include them in the ceteris paribus set. The details that obtain in 'close worlds' should vary in a way that makes the proposition false. However, whether or not the subject believes the proposition in these worlds would depend on which other details one holds the same. Otherwise, sensitivity theorists will end up arbitrarily suggesting that in 'close worlds' the subject believes or does not believe the proposition.

The correlation between relevant details and epistemic values only shows how relevant these details are. They cannot be treated as trivial details since the epistemic situation varies with them: change the details and there is a 
different epistemic situation. Surely a situation in which the subject truly believes $p$ is different from a situation in which the subject does not believe false proposition $p$. But what varies here other than the evidence of the subject, the facts that obtain, the subject's belief, the truth-value of the proposition, and the links in between? These are the things that make epistemic situations unique.

\section{Against Fallible Beliefs}

Objection 3: The analysis does not extend to all justified fallible beliefs.

Objection 4: Fallible beliefs do not qualify as knowledge.

I reply that sensitivity and safety do not have the mechanism to discriminate between justified fallible beliefs. Sensitivity and safety dislodged the justification condition; they do not qualify beliefs in terms of evidential support. The strength of one's evidence determines the strength of justification. It is not necessary for sensitivity and safety that justification or the evidence of the subject for believing the proposition is modally preserved (that the subject is justified in believing the proposition in close possible worlds). They only require the modal preservation of the link between belief and facts. So while they can discriminate between lucky and unlucky beliefs (luck here is defined in modal terms: if the link between belief and facts is modally preserved then there is no luck involved in the formation of the belief), they cannot discriminate between unjustified, less justified, and strongly justified fallible beliefs. But even if we suppose that these conditions can discriminate justified beliefs, sensitivity and safety theorists cannot add a justification condition without making their views incoherent, given that some justified beliefs are insensitive and unsafe (for example, A-type, B-type, and C-type beliefs)unless they accept that sensitivity and safety are not necessary conditions for knowing.

Moreover, even if sensitivity and safety theorists claim that modal conditions fail in A-type, B-type, and C-type cases but not in all cases of justified fallible beliefs, this will still imply that these conditions are not necessary for knowledge, since it cannot account for all knowledge cases. Now if they claim that all fallible beliefs do not qualify as knowledge, then that would defeat their arguments against skepticism, since these arguments assumed that our beliefs in ordinary propositions like "I have hands" are sensitive and safe, and these beliefs are fallible. This move will also make their views incoherent; attempts to solve this problem are motivated by the assumption that some fallible beliefs can generate knowledge, if all fallible beliefs do not

(c) 2019 Mark Anthony L. Dacela

https://www.kritike.org/journal/issue 24/dacela june2019.pdf

ISSN 1908-7330

(cc) BY-NC-ND 
qualify as knowledge, then the Gettier problem is not a problem-but sensitivity and safety are designed to solve this problem. Finally, if all fallible beliefs do not qualify as knowledge then only infallible beliefs do; this will imply that we do not know a lot of things. I also doubt if sensitivity and safety theorists can successfully offer an analysis of infallible beliefs. If they suppose that the set of evidences and facts are equivalent sets (and they have to, because if they are complementary or subsets then the subject's evidence is nonconclusive, and this makes the belief fallible) in cases that involve infallible beliefs, and if they take as equal all members of both sets, then the epistemic situation that will obtain in close possible worlds is exactly similar to the actual epistemic situation. This will make the modal conditions trivial.

\section{Against Epistemic Luck}

Objection 5: The analysis seems to imply that luck is compatible with knowledge, but lucky beliefs do not qualify as knowledge.

I reply that if my analysis implies anything about luck it is only that some instances of knowledge are compatible with the sort of luck sensitivity and safety theorists have in mind; that is, the nonmodal preservation of the link between belief and fact. It does not imply that luck is always compatible with knowledge.

That sensitivity and safety are not necessary for knowledge implies that in some instances of knowledge the link between belief and fact is not modally preserved. This is not inconsistent with the claim that some instances of knowledge are incompatible with the sort of luck sensitivity and safety theorists exclude in their analysis of knowledge, and the claim that lucky beliefs are insensitive or unsafe. My analysis could imply that it is not necessary to exclude the kind of luck that sensitivity and safety excludes, and not that knowledge is always compatible with luck; since it only shows that having insensitive and unsafe beliefs do not always defeat knowledge.

Our findings could imply that while sensitivity and safety tells us when a belief is lucky in some sort of way, whether or not this sort of luck is present may sometimes have little or nothing to do with actual knowledge cases; that something contrary to what actually happened would have happened in some possible circumstance may not undo the fact that it actually happened; that a subject would have still believed the proposition even if it were false (sensitivity) or that the proposition would have easily been false even if it were that the subject still believes it (safety) may not change the fact that the subject actually believed it and that the proposition is actually true, especially if these things are dependent on actual links that constitute the situation that 
actually obtains (and in most cases they are). But all I claim here is that there are instances of knowledge in which (1) the subject actually has a justified true belief, and in which (2) there is an actual link between belief and fact that is not modally preserved. And so, modal conditions are not necessary for knowledge.

Department of Philosophy, De La Salle University, Philippines

\section{References}

Baumann, Peter, "Is Knowledge Safe?" American Philosophical Quarterly, 45:1 (2008).

Bogardus, Tomas, "Knowledge Under Threat," Philosophy and Phenomenological Research, 88:2 (2014).

Briggs, Rachael and Daniel Nolan, "Mad, bad and dangerous to know," Analysis, 72:2 (2012).

Comesaña, Juan, “Unsafe knowledge," Synthese, 146 (2005).

Dacela, Mark Anthony, “Where Sensitivity Don't Work,” Suri, 6:2 (2017).

Freitag, Wolfgang, "Safety, Sensitivity and 'Distant' Epistemic Luck," Theoria, 80:1 (2014).

Gellman, Jerome, "A New Gettier Type of Refutation of Nozick's Analysis of Knowledge," Principia, 8:1 (2004).

Gettier, Edmund, "Is Justified True Belief Knowledge?" Analysis, 23 (1963).

Kelp, Christoph, "Knowledge and Safety," Journal of Philosophical Research, 34 (2009).

Lewis, David, Counterfactuals (Oxford: Blackwell Publishers, 1973). "Counterfactual Dependence and Time's Arrow," Noûs, 13 (1979).

Neta, Ram and Guy Rohrbaugh, "Luminosity and the Safety of Knowledge," Pacific Philosophical Quarterly 85 (2004).

Nozick, Robert, Philosophical Explanations (Cambridge, MA: Harvard University Press, 1981).

Sosa, Ernest, "How to Defeat Opposition to Moore," Philosophical Perspectives 13 (1999).

Stalnaker, Robert, "A Theory of Conditionals," in Studies in Logical Theory, ed. by Nicholas Rescher (Oxford: Blackwell, 1968).

Vogel, Jonathan, "Tracking, Closure, and Inductive Knowledge," in The Possibility of Knowledge: Nozick and his Critics, ed. by Luper-Foy Steven (Lanham, MD: Rowman \& Littlefield, 1987).

(c) 2019 Mark Anthony L. Dacela https://www.kritike.org/journal/issue 24/dacela june2019.pdf ISSN 1908-7330 